\title{
Tecnologias Digitais de Informação e Comunicação (TDICs) no ensino de Geografia nos anos finais do Ensino Fundamental
}

\author{
Rogério José Schuck ${ }^{1}$ \\ Rosmari Terezinha Cazarotto ${ }^{2}$ \\ Elaine Lima Santana ${ }^{3}$
}

\begin{abstract}
RESUMO
O presente estudo tem como tema as Tecnologias Digitais de Informação e Comunicação (TDICs) no processo de ensino de Geografia nos anos finais do Ensino Fundamental. Tal abordagem vai além de equipamentos como computadores, celulares e videogames. Esse conceito abrange as transformações ocorridas, sobretudo com o surgimento e a expansão da internet, que alteram os modos de vida e os relacionamentos nos mais diferentes setores e segmentos da sociedade, inclusive na educação. A metodologia adotada foi em torno das concepções da abordagem qualitativa, com pesquisa de campo, sob o enfoque fenomenológico. Como técnicas para a geração de dados, foram usadas observação, entrevista semiestruturada e aplicação de questionários. Os sujeitos da pesquisa foram 05 professores de Geografia e 26 alunos do $6^{\circ}$ ao $9^{\circ}$ ano do Ensino Fundamental em três escolas da rede municipal de ensino de Imperatriz - MA. Para tanto são apresentados os resultados da pesquisa sobre a percepção dos professores e alunos em relação às facilidades e/ou dificuldades que cercam o uso das TDICs e de que forma o uso dessas tecnologias pode contribuir, ou não, para o ensino dessa disciplina.
\end{abstract}

\footnotetext{
${ }^{1}$ Doutor em Filosofia pela PUCRS. Docente no PPGEnsino/Univates. Lajeado, RS, Brasil. https://orcid.org/00000001-9275-9193.rogerios@univates.br.

2 Doutora em Geografia pela UFRGS. Docente da Área das Humanidades, Univates. Lajead, RS, Brasil. https://orcid.org/0000-0001-8072-7346.rosmari.cazarotto@univates.br.

${ }^{3}$ Mestre em Ensino pela Univates. Técnica em Assuntos Educacionais da Universidade Federal do Maranhão, Imperatriz, MA, Brasil. https://orcid.org/0000-0002-6637-7842. elaineimp@gmail.com.
} 
PALAVRAS-CHAVE: Ensino. Geografia. Tecnologias Digitais de Informação e Comunicação.

Digital Information and Communication Technologies (TDICs) in the teaching of geography in the final years of elementary school

\begin{abstract}
:
This study has as its theme Digital Information and Communication Technologies (TDICs) in the process of teaching geography in the final years of elementary school. Such an approach goes beyond equipment such as computers, cell phones and video games. This concept encompasses the transformations that have occurred, especially with the emergence and expansion of the Internet, which change the ways of life and relationships in the most different sectors and segments of society, including education. The adopted methodology was around the conceptions of the qualitative approach, with field research, under the phenomenological focus. As techniques for data generation, observation, semi-structured interviews and questionnaires were used. The research subjects were 05 geography teachers and 26 students from 6th to 9th grade of elementary school in three schools of the municipal school of Imperatriz - MA. To this end, we present the results of research on the perception of teachers and students regarding the facilities and / or difficulties surrounding the use of ICTs and how the use of these technologies may or may not contribute to the teaching of this subject
\end{abstract}

KEYWORDS: Teaching. Geography. Digital Information and Communication Technologies.

Tecnologías Digitales de Información y Comunicación (TDIC) en la enseñanza de la geografía en los últimos años de la escuela primaria

\title{
RESUMEN
}

El presente estudio tiene como tema las Tecnologías Digitales de Información y Comunicación (TDIC) en el proceso de enseñanza de Geografía en los últimos años de la Escuela Primaria. Tal enfoque va más allá de equipos como computadoras, teléfonos celulares y videojuegos. Este concepto abarca las transformaciones que han ocurrido, 
especialmente con el surgimiento y la expansión de Internet, que cambian las formas de vida y las relaciones en los sectores y segmentos más diferentes de la sociedad, incluida la educación. La metodología adoptada fue en torno a las concepciones del enfoque cualitativo, con investigación de campo, bajo el enfoque fenomenológico. Como técnicas para la generación de datos, se utilizaron observaciones, entrevistas semiestructuradas y cuestionarios. Los sujetos de investigación fueron 05 maestros de geografía y 26 estudiantes de $6^{\circ}$ a $9^{\circ}$ grado de primaria en tres escuelas de la escuela municipal de Imperatriz - MA. Con este fin, presentamos los resultados de la investigación sobre la percepción de profesores y estudiantes sobre las instalaciones y / o dificultades que rodean el uso de las TIC y cómo el uso de estas tecnologías puede o no contribuir a la enseñanza de esta asignatura.

Palabras clave: Docencia. Geografía Tecnologías digitales de información y comunicación.

\section{Introdução}

O artigo apresenta como tema "As Tecnologias Digitais de Informação e Comunicação (TDICs) no processo de ensino de Geografia". As inquietações em relação ao assunto são oriundas da atuação docente, bem como da percepção acerca do rápido avanço tecnológico e do acesso, cada vez mais fácil e intenso, sobretudo dos jovens, às tecnologias digitais. Estas que têm influenciado o modo de vida, a postura humana no mundo e, inclusive, a maneira de ensinar e de aprender.

A escolha da terminologia TDICs, e não somente Tecnologia de Informação e Comunicação (TICs), se deve ao fato de se entender que as TDICs contemplam a configuração de tecnologia que se pretendeu pesquisar, como computadores, tablets, celulares, internet, entre outras tecnologias bastante usadas por jovens e adolescentes. 
Isso posto, acredita-se que o tema seja relevante, pois aborda um assunto atual e emergente. Sobretudo para ensinar e aprender geografia no ensino fundamental, pois, conforme Callai (2005) nesta etapa, é importante partir da leitura de mundo, do espaço de vida do aluno. Neste sentido, observar, compreender, dar significado ao espaço vivido para nele e, a partir dele, poder estabelecer conexões, tomar decisões sobre o ser no e do mundo. Enfim, fazer uso destas novas formas de comunicação para possibilitar a criação de condições para que as crianças leiam e possam atuar no espaço vivido. Exercitando assim, a sua cidadania.

\section{Tecnologias de Informação e Comunicação (TICs): fundamentos teóricos}

Existem diferentes terminologias utilizadas para se referir às tecnologias que vão surgindo a cada (r)evolução tecnológica. Tecnologias de Informação e Comunicação (TICs) é o termo mais encontrado em publicações acadêmicas. Outro termo que passou a ser utilizado com os avanços das telecomunicações é Novas Tecnologias da Informação (NTI) e, atualmente, com o uso de equipamentos digitais, tem-se adotado os seguintes termos: Novas Tecnologias de Informação e Comunicação (NTICs) e Tecnologias Digitais de Informação e Comunicação (TDICs).

A tecnologia está por toda parte. Dentro das nossas casas, no trabalho, nas ruas, nas atividades diárias, ela está sempre presente. De acordo com o dicionário Aurélio, tecnologia é a "ciência cujo objeto é a aplicação do conhecimento técnico e científico para fins industriais e comerciais". Nesse mesmo sentido, Brito e Purificação (2015, p. 22) definem tecnologia como "aplicação do conhecimento científico para se obter um resultado prático".

\section{As TDICs no contexto escolar}


Quando se fala em mudanças no cenário social, evidentemente a escola não pode ficar fora. A propagação rápida de conteúdos nos ambientes virtuais modifica o processo de aquisição de informação e/ou conteúdos, antes conseguidos apenas na escola, por meio do professor e do livro didático.

Dessa forma, outros ambientes de aprendizagem vão surgindo fora da sala de aula. Ou seja, assim como nos diversos campos da sociedade, no campo educacional, os avanços tecnológicos também trouxeram uma série de mudanças. "O sistema educacional baseado no livro e no professor como provedores primordiais da educação está desmoronando em virtude da penetração das tecnologias digitais no cotidiano das pessoas" (GABRIEL, 2013, p. 4).

É pertinente salientar que os avanços tecnológicos não se limitam somente aos novos usos de aparelhos, produtos e equipamentos, mas a novas formas de comportamento de indivíduos e grupos. Os recursos tecnológicos podem possibilitar mudanças nas formas de ensinar e de aprender, mas somente se houver uma análise crítica sobre sua utilização e mudanças na forma tradicional de fazer educação, no sentido de que a escola deixe de ser apenas reprodutora de informação.

De acordo com Mattar (2003), a informática gera uma revisão de nossos conceitos. Para o autor, a inteligência, por exemplo, deixa de ser concebida como acúmulo de informações e passa a ser entendida como habilidade para estabelecer conexões entre as informações. Essa nova tecnologia intelectual permite potencializar, além da memória, diferentes formas de raciocínio, entre outras habilidades.

Muitas vezes, as tecnologias são utilizadas apenas como recurso didático. Porém, para fazer a diferença, é preciso saber usá-las de forma pedagógica, pois "o que realmente importa em uma revolução tecnológica não é a tecnologia em si, mas o que fazemos com ela e como ela pode melhorar as nossas vidas" (GABRIEL, 2013, p. 3). Mais importante do que 
ter disponível as tecnologias digitais na escola, é saber usá-las para alcançar o objetivo principal do ensino que é a aprendizagem do aluno.

Nesse sentido, a comunidade escolar precisa se posicionar e decidir que relação pretende manter com essas tecnologias. Para Brito e Purificação (2015, p. 25), a comunidade escolar se depara com três caminhos, ou seja, pode repeli-las e tentar ficar fora do processo; apropriar-se da técnica e transformar a vida em uma corrida atrás do novo; ou apoderar-se dos processos, desenvolvendo habilidades que permitam o controle das tecnologias e de seus efeitos.

O fato é que as TDICs são uma realidade e a comunidade escolar já não pode mais ficar fora do processo. Contudo, simplesmente correr atrás do novo não vai provocar mudanças significativas. Torna-se necessário inserir essas tecnologias no processo educacional.

Dessa forma, é importante pensar em uma formação escolar que inclua as TDICs em prol da apropriação e da produção de conhecimentos. Para tanto, é essencial levar em consideração três questões, quais sejam, "acesso às máquinas (suporte), conexão com internet de qualidade (meio) e formação dos professores (mediadores)" (BRAGA; VÓVIO, 2015, p. 61).

Como os estudantes estão cada vez mais conectados com as tecnologias digitais, para conseguir alcançá-los é preciso que a escola também acompanhe os avanços tecnológicos, pois, além de ser responsável pelo acesso à informação e ao conhecimento, a escola também deve promover o reconhecimento da importância do uso das tecnologias. Por isso, a implantação de políticas públicas de inclusão digital das escolas, torna-se importante.

\section{O Ensino de Geografia no Ensino Fundamental}

A Geografia enquanto ciência é dinâmica e tem como objeto de estudo o espaço geográfico. Um conjunto indissociável de sistemas de objetos e sistemas de ações, entendidas como as relações estabelecidas entre os 
instrumentos de trabalho e as práticas sociais, respectivamente (SANTOS, 2014). A finalidade da geografia escolar é propiciar construção do pensamento geográfico. Desenvolver capacidades e habilidades de pensar a dimensão espacial (CALLAI, 2005).

A trajetória da consolidação da Geografia, tanto no âmbito acadêmico quanto escolar possui alguns marcos importantes. Destacaremos alguns marcos legais significativos no âmbito educacional brasileiro, a partir de 1990, sobretudo, com a promulgação da nova Lei de Diretrizes e Bases da Educação Nacional - LDBN 9394/96, os Parâmetros Curriculares Nacionais - PCN e a Base Nacional Comum Curricular (BNCC, 2017).

A LDB é a lei que define as diretrizes e as bases da organização do sistema educacional do país. Em outras palavras, é a lei geral da educação brasileira. Já os PCNs são documentos elaborados para servirem de apoio aos professores no planejamento de suas aulas, na seleção de materiais didáticos e de recursos tecnológicos. Estes devem ser utilizados para ajudar o professor na elaboração de um planejamento que possa, de fato, orientar seu trabalho em sala de aula com a finalidade de contribuir para o desenvolvimento do aluno. Sendo assim, os PCNs de Geografia (BRASIL, 1998, p. 15) propõem

Um trabalho pedagógico que visa à ampliação das capacidades dos alunos do Ensino Fundamental de observar, conhecer, explicar, comparar e representar características do lugar em que vivem e de diferentes paisagens e espaços geográficos.

Os PCNs de Geografia ressaltam, assim, a importância dessa disciplina na formação do cidadão e destacam o comprometimento dessa área de conhecimento no sentido de tornar o mundo compreensível e explicável aos alunos, passível de transformação. Dessa forma, "o ensino de Geografia pode levar os alunos a compreenderem de forma mais ampla a realidade, possibilitando que nela interfiram de maneira consciente e propositiva" (BRASIL, 1998, p. 25). 
Ainda de acordo com esse documento, um dos objetivos da disciplina de Geografia é "estudar as relações entre o processo histórico na formação das sociedades humanas e o funcionamento da natureza por meio da leitura do lugar, do território, a partir de sua paisagem”, a fim de compreender as relações entre sociedade e natureza, através das diferentes noções espaciais e temporais e dos fenômenos naturais, sociais e culturais (BRASIL, 1998, p. 26).

Atualmente, outro documento que visa nortear o processo de ensino é a Base Nacional Comum Curricular (BNCC), homologada no dia 20 de dezembro de 2017. Esse documento define os conhecimentos essenciais que todos os alunos da Educação Básica têm de aprender. A BNCC será a referência para a (re)elaboração dos currículos em todas as redes e escolas do país, públicas e privadas.

A BNCC ressalta a importância de se considerar as mudanças sociais promovidas pela cultura digital, em decorrência do avanço das tecnologias de informação e comunicação, considerando que os jovens estão cada vez mais engajados nessa cultura, e destaca que esse quadro impõe à escola desafios quanto à formação das novas gerações.

É importante que a instituição escolar preserve seu compromisso de estimular a reflexão e a análise aprofundada e contribua para o desenvolvimento, no estudante, de uma atitude crítica em relação ao conteúdo e à multiplicidade de ofertas midiáticas e digitais. Contudo, também é imprescindível que a escola compreenda e incorpore mais as novas linguagens e seus modos de funcionamento, desvendando possibilidades de comunicação (e também de manipulação), e que eduque para usos mais democráticos das tecnologias e para uma participação mais consciente na cultura digital. Ao aproveitar o potencial de comunicação do universo digital, a escola pode instituir novos modos de promover a aprendizagem, a interação e o compartilhamento de significados entre professores e estudantes (BRASIL, 2018). 
Espera-se que os alunos dos anos finais do Ensino Fundamental tenham maior autonomia em relação à leitura e à escrita e sejam capazes de compreender relações mais complexas do espaço geográfico; por isso, podem ser estimulados a expressarem seus pensamentos e opiniões por escrito.

Dessa forma, a disciplina de Geografia deve possibilitar que o aluno, no final do Ensino Fundamental, consiga compreender os conceitos de paisagem, território, de lugar e de região, identificando e avaliando as ações dos homens em sociedade em diferentes espaços e tempos e suas interações entre sociedade e natureza. Para Cavalcanti (2013, p. 11), "o conhecimento geográfico é, pois, indispensável à formação de indivíduos participantes da vida social, à medida que propicia o entendimento do espaço geográfico e do papel desse espaço nas práticas sociais".

Cabe salientar que a noção de espacialidade no contexto da expansão das tecnologias digitais, sobretudo, com a internet, extrapola o lugar físico de convívio dos indivíduos e se reconfigura como um espaço fluido, sem limites geográficos definidos. É o que teóricos como Lévy (1999) caracterizam como ciberespaço.

Nesse sentido, a BNCC ressalta que, nessa etapa do Ensino Fundamental, é preciso que os alunos ampliem seus conhecimentos sobre o uso do espaço em diferentes situações geográficas, considerando também o espaço virtual proporcionado pela rede mundial de computadores. De acordo com a BNCC, espera-se que o estudo da Geografia nos anos finais do Ensino Fundamental contribua para

[...] o delineamento do projeto de vida dos jovens alunos, de modo que eles compreendam a produção social do espaço e a transformação do espaço em território usado. Anseia-se, também, que entendam o papel do Estado-nação em um período histórico cuja inovação tecnológica é responsável por grandes transformações socioespaciais, acentuando ainda mais a necessidade de que possam conjecturar as alternativas de uso do território e as possibilidades de seus próprios projetos para o 
futuro. Espera-se, também, que, nesses estudos, sejam utilizadas diferentes representações cartográficas e linguagens para que os estudantes possam, por meio delas, entender o território, as territorialidades e o ordenamento territorial em diferentes escalas de análise (BRASIL, 2018, texto digital).

\section{As TDICs e as possibilidades para o Ensino de Geografia na nova reconfiguração do espaço}

Historicamente, a educação escolar sempre esteve voltada à função reprodutiva do sistema vigente. Inicialmente, servia para disciplinar, moldar comportamentos. No caso específico da Geografia, contribuiu com a construção da nacionalidade e do patriotismo. Posteriormente, com o advento industrial, a educação passou a servir de produtora de mão de obra para atender ao mercado. No contexto atual, porém, já não cabe mais uma educação escolar disciplinadora, reprodutiva, usada como instrumento de adequação do futuro profissional ao mundo do trabalho.

A sociedade, decorrente da revolução tecnológica e seus desdobramentos na área da informação e comunicação, exige uma educação voltada para a formação de cidadãos autônomos, críticos, ativos e criativos. Cavalcanti (2013, p. 15) apresenta vários termos utilizados para caracterizar essa nova sociedade.

Anuncia-se, nesta virada de século, um contexto complexo. Termos como sociedade pós-industrial, sociedade pós-capitalista, sociedade pósmoderna, revolução informacional, terceira revolução industrial, revolução tecnocientífica, sociedade informática têm sido utilizados para denominar os fenômenos socioeconômicos, culturais e políticos que têm caracterizado a sociedade contemporânea. Esse novo momento histórico pode ser denominado "era da internet" ou "era digital", marcada pelos "computadores e suas conexões via Internet" (FILÉ, 2011, p. 33). 
"A Era da internet foi aclamada como o fim da geografia" (CASTELLS, 2003, p. 170). Isso não significa dizer que o surgimento da internet tenha determinado o fim da geografia, mas que a internet tem uma geografia própria, e que com ela surgem novas configurações territoriais com concentrações, descentralizações e conexões espaciais. O referido autor trata especificamente da geografia da própria internet e das influências das tecnologias de informação e comunicação sobre a transformação espacial de cidades e regiões. Ainda nesse sentido, Tarja (2008, p.190) ressalta que a internet é:

[...] uma mudança/ação do homem sobre a natureza. Ela permite a transmissão cultural pluralista de forma digital, sobrepondo-se aos empecilhos temporais e geográficos. A internet é um canal de transmissão cultural/multicultural. Ela promove a hominização digital.

Milton Santos (2014), ao considerar o espaço geográfico (e com ele, a chegada da cibernética) e o avanço das técnicas, diz que, no atual período, ao mesmo tempo em que o espaço geográfico é um meio, está se construindo um meio técnico-científico-informacional. Assim, tem havido uma crescente tecnificação do espaço em escala planetária, uma crescente universalização das técnicas como fato e como processo. Isso acelera os fluxos e aproxima lugares. Esse fenômeno constitui-se em um novo paradigma para a humanidade.

Entende-se a emergência do meio técnico-científico-informacional, o atual momento em que se encontra o sistema capitalista de produção e transformação do espaço geográfico, que vem se reconfigurando desde a segunda metade do século XX a partir da Terceira Revolução Industrial, com a expansão do processo de globalização e, sobretudo, a partir da década de 1970, com a internet. 
Nesse contexto, a disciplina de Geografia tem papel fundamental, pois ajuda o indivíduo a compreender a organização do espaço e a sua função na sociedade. Para tanto, precisa apropriar-se de conceitos que o ajudem a construir e a reconstruir o conhecimento geográfico, o que pode ocorrer fora da escola; porém, é na escola que os conhecimentos geográficos devem sair do senso comum e serem "potencializados com práticas intencionais de intervenção pedagógica" (CAVALCANTI, 2013, p. 12).

Sendo assim, torna-se necessário desapegar-se de um ensino baseado apenas na descrição dos fatos e embasado quase que unicamente no livro didático. De um ensino que tem como objetivo, ao final, avaliar apenas se o aluno memorizou, ou não, os conteúdos e os conceitos trabalhados, em vez de avaliar a compreensão dos conceitos e do conteúdo pelos alunos e sua capacidade de problematizar e de resolver situações diversas. Percebe-se que a abordagem conteudística da disciplina faz com que ela, muitas vezes, seja rotulada pelos alunos como enfadonha e insignificante.

No estudo da disciplina de Geografia, faz-se necessário o entendimento de conceitos e categorias da ciência geográfica, como lugar, paisagem, região, território, e espaço geográfico, partindo de uma análise da relação da sociedade com o meio em que vive. Dessa forma, os objetivos de estudo da disciplina de Geografia na escola devem estar voltados, principalmente, para a compreensão da produção e da organização do espaço geográfico de maneira integrada aos fatores que determinam essa produção e organização, levando os alunos a pensarem sobre seu espaço de forma mais ampla e crítica. Conforme argumenta Cavalcanti (2013, p.24):

A finalidade de ensinar Geografia para crianças e jovens deve ser justamente a de os ajudar a formar raciocínios e concepções mais articulados e aprofundados a respeito do espaço. Trata-se de possibilitar aos alunos a prática de pensar os fatos e acontecimentos enquanto constituídos de múltiplos determinantes; de pensar os fatos e acontecimentos mediante várias explicações, 
dependendo da conjugação desses determinantes, entre os quais se encontra o espacial.

Para se atingir essa finalidade, já não se pode mais ensinar Geografia como há décadas, pois essa nova configuração de espaço exige que se relacione o espaço real, onde todas as representações humanas se estabelecem num espaço físico, com um espaço virtual ou ciberespaço. De acordo com Lévy (1999, p. 17), o ciberespaço é "o novo meio de comunicação, que surge da interconexão mundial de computadores”.

Contudo, o ciberespaço não deve ser entendido apenas como um espaço composto por instrumentos (computador) e tecnologias (internet), mas também, como um espaço habitado por indivíduos dotados de saberes, que gera novas formas de relações sociais e que não está restrito a limitações geográficas. Esse espaço, virtual ou ciberespaço, intensificou as transformações na sociedade, denominada por Castells (2008) de "sociedade em rede”. Com o surgimento da internet, criou-se um novo espaço para a comunicação, informação e difusão de conhecimento.

De acordo com Kenski (2012, p. 34), "Chamada de rede das redes, a internet é o espaço possível de integração e de articulação de todas as pessoas conectadas com tudo o que existe no espaço digital, o ciberespaço". O ciberespaço reconfigura a organização da sociedade no espaço, pois altera a forma como as pessoas se relacionam, pensam e dão sentido ao mundo.

Para Santaella (2004, p. 45), o ciberespaço é “um espaço informacional, no qual os dados são configurados de tal modo que o usuário pode acessar, movimentar e trocar informação com um incontável número de outros usuários". Ressalta-se que isso ocorre em qualquer lugar e a qualquer momento, levando muitas vezes os indivíduos a um distanciamento das referências de tempo e espaço.

A inserção das Tecnologias Digitais de Informação e Comunicação no ensino de Geografia permite o acesso de uma maior quantidade de registro de informações geográficas em forma digital, possibilitando o estudo dos 
conceitos e das categorias da Geografia através de fotografias aéreas, imagens de satélite, cartas geográficas, mapas, entre outros recursos. O cinema, os filmes e as músicas também contribuem como recursos tecnológicos para o estudo da Geografia. Hoje, com a convergência das tecnologias, tudo isso pode ser encontrado no computador ou smartphones com acesso à internet, por exemplo. Antes, todos esses recursos estavam separados.

Nesse sentido, de acordo com os PCNs e Geografia (BRASIL, 1998, p. 142), "o recurso tecnológico é usado como um meio didático no processo de ensino-aprendizagem. Mediante o uso das tecnologias da comunicação, é possível problematizar os conteúdos específicos de Geografia”. Além disso, os PCNs para o Ensino Fundamental prescrevem, entre os objetivos dessa etapa de ensino, que os alunos sejam capazes de saber utilizar diferentes fontes de informação e recursos tecnológicos para adquirir e construir conhecimento.

O uso dos recursos tecnológicos pode auxiliar no processo de ensino e de aprendizagem da Geografia, tendo em vista que as aulas tradicionais, baseadas na memorização do conteúdo, são extremamente cansativas, desestimulantes e fazem com que os alunos percam o interesse por essa disciplina.

Contudo, é preciso estabelecer um caráter menos instrumental a essas tecnologias. Não basta aprender a usá-las; é preciso interagir e participar socialmente, compreendendo o mundo em que se vive e se integrando a esse novo espaço que surge.

Atualmente, estão disponíveis diversos sites, programas e aplicativos que podem ser usados nas aulas de Geografia. Sites como o do Instituto Brasileiro de Geografia e Estatística (IBGE), do Instituto Brasileiro do Meio Ambiente e dos Recursos Naturais Renováveis (IBAMA) trazem uma série de dados e informações que podem enriquecer as aulas de Geografia. Programas como o Google Maps, que pode ser utilizado nos estudos cartográficos, e o Google Earth, que apresenta um modelo tridimensional do 
globo terrestre, podem ser usados no estudo das diversas paisagens presentes no Planeta Terra. Gabriel (2013, p. 220) destaca que "O aplicativo Google Search tem uma funcionalidade (Google Goggles) que permite a busca por imagens e fotografias de lugares”, e que essa busca pela imagem de um lugar resulta em informações sobre ele.

Além disso, outras tecnologias digitais, como os videogames, por exemplo, constituem-se como ferramentas de ensino e aprendizagem, pois os jogos representam um grande potencial educacional. De acordo com Gabriel (2013, p. 219): “Os jogos incentivam a colaboração e a interação para solução de problemas, e os jogadores estão sempre motivados e dispostos a tentar novamente quando falham”. Dessa forma, podem ser inseridos jogos nas aulas, com temas trabalhados na disciplina de Geografia, para que os alunos possam criar hipóteses para resolver problemas como a fome no mundo, a pobreza, conflitos globais, catástrofes ambientais etc.

Uma das principais tendências atuais no ambiente digital são os vídeos, que também trazem muitas possibilidades educacionais. O professor pode baixar, e levar para a sala, vídeos com diferentes temas; pode indicar vídeos para os alunos assistirem em casa no computador, ou mesmo no celular; ou pode produzir vídeos individualmente ou com os alunos. O Youtube, o maior e mais popular site de compartilhamento de vídeos on-line do mundo, tem um serviço especial focado em educação. Gabriel (2013, p. 214) destaca que "As escolas podem criar suas contas no YouTube EDU para disponibilizarem os seus conteúdos em vídeo. O YouTube EDU também oferece uma área específica para professores".

Diante do exposto, cabe ressaltar que o professor precisa apropriar-se das inovações tecnológicas, assimiladas tão facilmente pelos alunos, mudando sua postura frente às possibilidades trazidas pelas TDICs. Para Silva (2011, p. 82, grifo do autor), é preciso "modificar o modelo centrado no falar-ditar do mestre", disponibilizando, aos alunos, ferramentas que possibilitem a eles serem autores no seu processo de aprendizagem. 


\section{Percurso metodológico}

A metodologia adotada foi em torno das concepções da abordagem qualitativa, com pesquisa de campo, sob o enfoque fenomenológico, o qual de acorde com Gil (2012, p. 14 -15), "parte do cotidiano, da compreensão do modo de viver das pessoas, e não de definições e conceitos”, procurando "resgatar os significados atribuídos pelos sujeitos ao objeto que está sendo estudado". Como técnicas para a geração de dados, foram usadas a observação com registros em diário de campo, entrevistas semiestruturadas e a aplicação de questionários com questões fechadas e abertas. O lócus da pesquisa foram 03 escolas da Rede Municipal de Ensino de Imperatriz- MA. Os sujeitos pesquisados foram 05 professores de Geografia que atuam nos anos finais do Ensino Fundamental, nos turnos matutino e/ou vespertino, além de 26 alunos do $6^{\circ}$ ao $9^{\circ}$ ano dessas escolas.

Tanto as escolas quanto os sujeitos da pesquisa tiveram suas identidades preservadas para garantir o anonimato e possibilitar que os entrevistados se sentissem mais à vontade para falar. Dessa forma, as escolas pesquisadas foram identificadas como E1, E2 e E3. Os professores entrevistados foram identificados como P1, P2, P3, P4 e P5 e os alunos como $\mathrm{A} 1, \mathrm{~A} 2$ até $\mathrm{A} 26$.

A partir das entrevistas, da aplicação do questionário e das observações realizadas pode-se vislumbrar discursos de professores e alunos sobre o fenômeno das TDICs no ensino de Geografia nos anos finais do Ensino Fundamental.

O questionário aplicado aos alunos foi construído com o intuito de buscar conhecer o perfil desses sujeitos e averiguar junto a eles como as Tecnologias Digitais de Informação e Comunicação são utilizadas pelos professores de Geografia. De posse desses dados, buscou-se confrontá-los com as informações fornecidas pelos professores nas entrevistas realizadas. Assim, professores e alunos foram questionados sobre as TDICs existentes na escola em que trabalham e estudam, respectivamente. 


\section{Resultados e análise das respostas dos professores e alunos}

Constatou-se por meio das observações realizadas e informações fornecidas pelos docentes que as TDICs mais citadas por ambos foram o projetor multimídia (datashow) e o laboratório de informática (computadores). Apesar de as três escolas possuírem laboratório de informática, esses não estão em funcionamento, seja por problemas de manutenção do espaço físico, problema nos equipamentos ou por falta de internet. Pelo que foi levantado, porém, os laboratórios das escolas E1 e E2, mesmo com pequena quantidade de equipamentos, funcionavam com internet até pouco tempo antes da realização desta pesquisa. Já o laboratório de E3 há mais de quatro anos não funciona.

Quanto ao projetor multimídia, verificou-se que só existe um único aparelho em cada uma das escolas pesquisadas, para ser utilizado por todos os professores e, para usá-lo, os professores precisam reservar junto às secretarias das escolas. Na escola E2 esse aparelho fica instalado na sala denominada de sala de vídeo.

Ressalta-se que esse equipamento por si só é apenas uma ferramenta tecnológica. O uso que se faz dele é que se caracteriza como uma TDIC. Conectado à internet, ele pode ser utilizado on-line para toda a turma visualizar ao mesmo tempo os sites que o professor acessar, como, por exemplo, o Google Maps citado por P1 e P4 quando foram questionados sobre aplicativos, sites ou programas que conhecem e que podem ser usados para auxiliar no ensino de Geografia. Dessa forma, todos os alunos poderão interagir ao mesmo tempo, tirando dúvidas, contribuindo com colocações acerca do conteúdo que está sendo trabalhado e exibido em tela para a turma.

Sem conexão com a internet, o projetor multimídia pode ser usado para exibir filmes ou documentários, como P3 e P4 afirmaram utilizar em suas aulas, transformando a sala de aula em sala de cinema. Ou pode ser 
usado também para exibir apresentações em PowerPoint, feitas pelo professor ou pelos próprios alunos, conforme mencionou P2, que pede para os alunos pesquisarem determinado conteúdo e eles já montam os slides com apresentação da pesquisa.

Quando os alunos foram questionados se os professores de Geografia utilizam as TDICs em suas aulas, 12 dos 26 alunos responderam que não. Todos os alunos que estudam com P2 responderam que esse professor não utiliza nenhuma TDIC em suas aulas, confirmando as informações fornecidas pelo docente na entrevista, em que reconheceu que quase não usa porque não sabe operar os equipamentos tecnológicos. Nesse caso, nota-se a necessidade da formação e/ou capacitação do professor para o uso adequado das tecnologias digitais.

Dos 4 alunos que estudam com P5, apenas 1 informou que o professor utiliza TDICs em suas aulas, apesar desse docente informar na entrevista que usa em suas aulas inclusive o celular. Já os 6 alunos que estudam com P4 responderam em unanimidade que o professor usa TDICs em suas aulas. Ressalta-se que esse professor foi o que demonstrou maior interesse pela temática durante a entrevista.

Durante a pesquisa notou-se, através dos depoimentos dos professores, que eles percebem como benéfico o uso das TDICs no ensino; afirmam utilizar essas tecnologias para o planejamento de suas aulas, buscando algo além do que vem sugerido nos livros didáticos e compreendem que essas tecnologias têm muito a contribuir para o ensino da Geografia. No entanto, pouco foi apontado sobre o uso efetivo dessas tecnologias em sala de aula. O fato de não haver rede Wi-Fi disponível na escola para os alunos e de os laboratórios não estarem funcionando pode ser um dos motivos para isso. Dessa forma, o uso das TDICs fica praticamente restrito à realização dos planejamentos e à elaboração de atividades pelos professores.

Dos 26 alunos participantes da pesquisa, 23 informaram que a Tecnologia Digital de Informação e Comunicação mais utilizada por eles é o celular. Nota-se, com essa informação, que quase todos os alunos possuem 
um aparelho celular disponível para uso. Porém, um professor colaborador (P4) enfatiza que muitas vezes não usa o celular em sala porque os alunos não possuem esse aparelho. Essa mesma informação é dada outro docente (P5) que lamenta o fato de ter "aluno na escola pública que nunca abriu um computador, infelizmente. Alguns não têm nem acesso ao celular”.

Tanto para os professores, quanto os alunos pesquisados, percebe-se que o uso do celular como uma ferramenta de ensino e aprendizagem quase não é mencionado. Um docente (P5) diz que P5 diz não usar porque na escola não tem internet e outro docente (P4) informa que às vezes não usa porque a maioria dos alunos não possui esse aparelho. Já P1 afirma que não usa com os seus alunos em sala porque se "não direcionar às vezes eles não sabem usar". Nesse sentido, Moran (2013, p. 58) ressalta que "As tecnologias móveis, bem utilizadas, facilitam a interaprendizagem, a pesquisa em grupo, a troca de resultados [...] Infelizmente, muitos se perdem na dispersão superficial da banalidade repetitiva".

Ainda nesse sentido, o celular conectado à internet, se não utilizado adequadamente, pode resultar em inconveniente para a escola. Gabriel (2013, p. 204) ressalta que "A internet pode ser uma ferramenta formidável, mas também pode ser um instrumento de desgraça”. A autora alerta sobre os perigos do cyber-bullying, da autoexposição, da perda da privacidade e sobre o cuidado que se deve ter ao se expor ou expor outras pessoas. A referida autora ressalta ainda a importância da educação digital, que vai além de saber manusear equipamentos digitais.

Apesar de a grande maioria dos alunos afirmar possuir celular, e todos afirmarem ter acesso à internet, menos de um terço dos alunos informa usar internet para atividades relacionadas a estudos. Apenas 1 aluno dos 26 sujeitos da pesquisa menciona que o celular é uma das TDICs utilizadas pelo professor. Outro dado que chama atenção é que apenas 06 alunos sugerem aos professores de Geografia que utilizem o celular em suas aulas. Nota-se que esses dados são contraditórios as afirmações dadas pelos docentes sobre o acesso dos alunos ao celular. 
Acredita-se que o fato de os professores não utilizarem essa ferramenta tecnológica como recurso pedagógico e, muitas vezes, até proibirem seu uso em sala, pode ser um dos motivos que levam os alunos a não perceberem o celular como ferramenta de aprendizagem.

Assim como nas respostas dos professores, o Google também se destaca nas respostas dos alunos quando questionados sobre sites, programas e/ou aplicativos que podem ser usados nas aulas de Geografia. Os sites de busca disponibilizam rapidamente uma grande quantidade de informações sobre um tema pesquisado. Contudo, Gomez (2013, p. 25) ressalta que "a busca, permite excelentes achados, mas também pode trazer textos duvidosos, conteúdo difícil de identificar o autor". Por isso "o professor precisa aprender a pesquisar antes de ensinar aos seus alunos" (BRITO; PURIFICAÇÃO, 2015, p. 106).

Já os blogs só foram mencionados por um docente (P5), que informa utilizar blogs de outros professores como fonte de pesquisa. Além de servirem como fonte de informação, os blogs podem ser criados em conjunto, pelo professor e os alunos, para abrigar assuntos referentes à disciplina de Geografia, por exemplo. Nele, professores e alunos podem publicar atividades, projetos realizados, fotografias, vídeos, links etc. Sobre a contribuição dos blogs, Leite (2014, p. 70) corrobora que "a interação entre os participantes do blog pode facilitar o processo de construção de conhecimento coletivo, esta tecnologia pode ajudar a formar redes sociais e redes de saberes, conhecimentos".

O videogame foi citado como uma TDIC por apenas 1 dos alunos e não foi mencionado por nenhum dos docentes. Sobre os games, Kenski (2012, p. 116) ressalta que "Em suas casas ou em lanhouses, os jovens dedicam-se com prazer ao que mais gostam de fazer, jogar em rede". Se as competências e habilidades desenvolvidas por esses alunos forem transferidas para o desenvolvimento das aprendizagens escolares, podem fazer uma grande diferença. 
Kenski (2012, p. 119) aponta também que "os learning games (LGames), como são chamados os jogos para aprendizagem”, trazem uma série de possibilidades de criação, interação, cooperação, dentre outras. Moran (2013, p. 33) corrobora que "Os jogos digitais estarão cada vez mais presentes nesta geração, como atividades essenciais de aprendizagem". Dessa forma, o videogame enquanto equipamento ou os jogos digitais instalados nos computadores ou smartphones podem se configurar como ferramentas educacionais, dependendo do seu uso.

As redes sociais, como o Facebook e o WhatsApp, não foram citadas pelos sujeitos da pesquisa como ferramentas pedagógicas, apesar de servirem como redes de relacionamento entre alunos e professores, aumentando a proximidade entre eles. Esse é um espaço que os professores podem aproveitar para compartilhar links referentes aos conteúdos das aulas, para informar e orientar os alunos sobre atividades a serem realizadas.

Cabe ressaltar que ensinar e aprender utilizando as tecnologias digitais é um desafio da escola, do professor e do aluno, que muitas vezes vê essas tecnologias apenas como entretenimento. Nesse sentido, Moran (2013, p. 57) ressalta que "Alunos e professores tendem a dispersar-se diante de tantas conexões possíveis, de endereços dentro de outros endereços, de imagens, textos e mensagens". Mesmo assim, é preciso parar para refletir sobre a necessidade e o uso adequado dessas tecnologias no ambiente escolar.

Um ponto que ficou bastante evidenciado através dos relatos dos docentes e nas respostas obtidas no questionário aplicado aos alunos foi a insatisfação quanto à falta de acesso às TDICs nas escolas. Além disso, ficou clara também a necessidade de formação continuada dos professores.

\section{Conclusão}


Embora as TDICs estejam presentes na sociedade atual, sua inserção na escola ainda ocorre de forma lenta, os profissionais da educação e a própria estrutura educacional da rede pública de ensino ainda não estão totalmente preparados para lidar com tais inovações que surgem com a era digital.

Acredita-se que a inserção das TDICs no processo de ensino de Geografia pode promover inúmeras possibilidades. Para tanto, é fundamental que o professor, através de uma metodologia e de um planejamento adequado, atue como mediador nesse processo, motivando o aluno na utilização das TDICs para seu maior crescimento.

Verifica-se, portanto, além da falta de acesso às TDICs nas escolas, outro problema, a saber, a necessidade de formação continuada para os professores. Cabe, assim, ao poder público, investir em programas de inclusão digital nas escolas, que abranjam, além da compra de equipamentos, condições de manutenção destes, melhores condições de trabalho e formação para os profissionais.

\section{Referências}

BRAGA, D. B.; VÓVIO. C. L. Uso de tecnologia e participação em letramento digitais em contextos de desigualdade. In: BRAGA, D. B. (Org.). Tecnologias digitais da informação e comunicação e participação social: possibilidades e contradições. São Paulo: Cortez, 2015.

BRASIL. Secretaria de Educação Fundamental. Parâmetros curriculares nacionais: geografia / Secretaria de Educação Fundamental. Brasília: MEC/SEF, 1998. 156p.

Ministério da Educação. Base Nacional Comum Curricular. Brasília: MEC, 2017. Disponível em: http://basenacionalcomum.mec.gov.br/a-base/. Acesso em: 23 mar. 2018.

BRITO, G. da S.; PURIFICAÇÃO, I. da. Educação e novas tecnologias: um (re)pensar. 2. ed. Curitiba: Editora InterSaberes, 2015. (Série Tecnologias Educacionais).

CALLAI, Helena C. Aprendendo a ler o mundo: A geografia nos anos iniciais do ensino fundamental. Cad. CEDES [online]. 2005, vol.25, n.66, pp.227-247. Disponível em: http://www.scielo.br/scielo.php?script=sci_arttext\&pid=S010132622005000200006. Acesso em: 11 mai. 2018. 
CASTELLS, Manuel. A galáxia da internet: reflexões sobre a internet, os negócios e a sociedade. Tradução de Maria Luiza X. de A. Borges. Revisão técnica de Paulo Vaz. Rio de Janeiro: Jorge Zahar Ed., 2003.

A sociedade em rede. 11. ed. São Paulo: Paz e Terra, 2008.

CAVALCANTI, Lana de Souza. Geografia, escola e construção de conhecimento. 18. ed. 3. reimpr. Campinas, SP, 2013. (Coleção Magistério: Formação e Trabalho Pedagógico, 2014).

FERNANDES, Magali. A Pedagogia de um Projeto Multimídia. In: DOMINGUES. A. M.;

FERNANDES, M.; GOMEZ, M. V. (Orgs.). Educar na contemporaneidade: cultura, tecnologia e educação no cotidiano do professor e do estudante (Pedagogia de A a Z). Jundiaí: Paco Editorial, v. 9, 2013.

FILÉ, Valter. Novas Tecnologias, antigas estruturas de produção de desigualdades. In: FREIRE, W. (Org.). Tecnologia e Educação: as mídias na prática docente. 2. ed. Rio de Janeiro: Wak Ed., 2011.

FREIRE, Paulo. Educação como prática da liberdade. Rio de Janeiro: Paz e Terra, 2007.

A importância do ato de ler. São Paulo: Cortez, 1989.

GABRIEL, Martha. Educar: a revolução digital na educação. 1. ed. São Paulo: Saraiva, 2013.

GIL, Antonio Carlos. Métodos e técnicas de pesquisa social. 6. ed. 5. Reimpr. São Paulo: Atlas, 2012.

GOMEZ, M. V. Educar pela pesquisa - Dispositivos da web para a Investigação Científica. In: DOMINGUES. A. M.; FERNANDES, M.; GOMEZ, M. V.; (Orgs.). Educar na contemporaneidade: cultura, tecnologia e educação no cotidiano do professor e do estudante (Pedagogia de A a Z). Jundiaí: Paco Editorial, v. 9, 2013.

KENSKI, Vani Moreira. Educação e tecnologias: o novo ritmo da informação. 8. ed. 5. reimpr. Campinas, SP, 2012. (Coleção Papirus Educação, 2015).

LEITE, Lígia Silva (Coord.). Tecnologia Educacional: descubra suas possibilidades na sala de aula. 8. ed. Petrópolis, RJ: Vozes, 2014.

LÉVY, Pierre. Cibercultura. Tradução de Carlos Irineu da Costa. São Paulo: Ed. 34, 1999. (Reimpr. 2010).

MÁTTAR, Neto; AUGUSTO, João. Metodologia científica na era da informática. São Paulo: Saraiva, 2003.

MORAN, José Manuel. Ensino e Aprendizagem Inovadores com Apoio de Tecnologias. In: MORAN, José Manuel; MASETTO, Marcos T.; BEHRENS, 
Marilda Aparecida. Novas Tecnologias e Mediação Pedagógica. 21. ed. Campinas: Papirus, 2013. Cap. 1. p. 11-72.

PRENSKY, Marc. Digital natives, digital immigrants. On the Horizon, HBC University Press, v. 9, n. 5, oct. 2001.

SAMPAIO, M. N.; LEITE, L. S. Alfabetização tecnológica do professor. 10. ed. Petrópolis,

RJ: Vozes, 2013.

SANTAELLA, Lúcia. Navegar no ciberespaço: o perfil cognitivo do leitor imersivo. São Paulo: Paulus, 2004.

SANTOS, M. A Natureza do espaço: Técnica e tempo, Razão e emoção. 4. ed. 8 reimpressão. São Paulo: Edusp, 2014.

PONTUSCHKA, N. N.; PAGANELLI, T. I; CACETE, N.H. Para Ensinar e Aprender Geografia. São Paulo: Ed. Cortez, 2007. 383p.

SILVA, Marco. Os professores e o desafio comunicacional da cibercultura. In: FREIRE, Wendel (Org.). Tecnologia e educação: as mídias na prática docente. 2. ed. Rio de Janeiro: Wak Ed., 2011.

TAJRA, Sanmya Feitosa. Informática na Educação: novas ferramentas pedagógicas para o professor na atualidade. 8. ed. revisada e ampliada. São Paulo: Ética, 2008

Recebido em 30 de novembro de 2019.

Aprovado em fevereiro de 2020. 